\title{
Acute Effects of Transforming Growth Factor- $\beta 1$ on Neuronal Excitability and Involvement in the Pain of Rats with Chronic Pancreatitis
}

\author{
Xiaoyu Zhang, ${ }^{1}$ Hang Zheng, ${ }^{1}$ Hong-Yan Zhu, ${ }^{2}$ Shufen Hu, ${ }^{1}$ Shusheng Wang, ${ }^{2}$ Xinghong Jiang, ${ }^{1}$ and Guang-Yin Xu ${ }^{1,2 *}$ \\ ${ }^{1}$ Jiangsu Key Laboratory of Translational Research and Therapy for Neuro-Psycho-Diseases, Institute of Neuroscience, Soochow University, \\ Suzhou, China; and ${ }^{2}$ Center for Translational Medicine, the Affiliated Zhangjiagang Hospital of Soochow University, Zhangjiagang, China
}

\section{Background/Aims}

This study was to investigate whether transforming growth factor- $\beta 1$ (TGF- $\beta 1$ ) plays a role in hyperalgesia in chronic pancreatitis (CP) and the underlying mechanisms.

\section{Methods}

CP was induced in male adult rats by intraductal injection of trinitrobenzene sulfonic acid (TNBS). Abdominal hyperalgesia was assessed by referred somatic behaviors to mechanical stimulation of rat abdomen. Dil dye injected into the pancreas was used to label pancreas-specific dorsal root ganglion (DRG) neurons. Whole cell patch clamp recordings and calcium imaging were performed to examine the effect of TGF- $\beta 1$ on acutely isolated pancreas-specific DRG neurons. Western blot analysis was carried out to measure the expression of TGF- $\beta 1$ and its receptors.

\section{Results}

TNBS injection significantly upregulated expression of TGF- $\beta 1$ in the pancreas and DRGs, and TGF- $\beta 1$ receptors in DRGs (T9-T13) in CP rats. Intrathecal injection of TGF- $\beta$ receptor I antagonist SB431542 attenuated abdominal hyperalgesia in CP rats. TGF- $\beta 1$ application depolarized the membrane potential and caused firing activity of DRG neurons. TGF- $\beta 1$ application also reduced rheobase, hyperpolarized action potential threshold, and increased numbers of action potentials evoked by current injection of pancreas-specific DRG neurons. TGF- $\beta 1$ application also increased the concentration of intracellular calcium of DRG neurons, which was inhibited by SB431542. Furthermore, intrathecal injection of TGF- $\beta 1$ produced abdominal hyperalgesia in healthy rats.

\section{Conclusions}

These results suggest that TGF- $\beta 1$ enhances neuronal excitability and increases the concentration of intracellular calcium. TGF- $\beta 1$ and its receptors are involved in abdominal hyperalgesia in CP. This and future study might identify a potentially novel target for the treatment of abdominal pain in CP.

(J Neurogastroenterol Motil 2016;22:333-343)

Key Words

Abdominal pain; Chronic pancreatitis; Dorsal root ganglion; Transforming growth factor beta 1

Received: July 31, 2015 Revised: October 31, 2015 Accepted: November 22, 2015

(a) This is an Open Access article distributed under the terms of the Creative Commons Attribution Non-Commercial License (http://creativecommons. org/licenses/by-nc/4.0) which permits unrestricted non-commercial use, distribution, and reproduction in any medium, provided the original work is properly cited.

${ }^{*}$ Correspondence: Guang-Yin Xu, MD, PhD

Laboratory for Translational Pain Medicine, Institute of Neuroscience, Soochow University, 199 Ren-Ai Road, Suzhou 215123, China

Tel: +86-512-65882817, Fax: +86-512-65883806, E-mail: guangyinxu@suda.edu.cn

Xiaoyu Zhang and Hang Zheng contributed equally to this work. 


\section{Introduction}

Chronic pancreatitis (CP) is a common disease characterized by persistent inflammation, parenchymal fibrosis, and destruction of the glandular pancreas. ${ }^{1}$ The most clinically relevant feature of $\mathrm{CP}$ is recurrent upper abdominal pain, which is not only intense and persistent but also difficult to treat. ${ }^{1}$ The pathobiological mechanisms of pain in $\mathrm{CP}$ are incompletely understood, which makes obstacles in developing novel effective therapeutic approaches. Although central sensitization inevitably follows, sensitization of peripheral nociceptors is the critical and initiating event in pain caused by local inflammation. ${ }^{2}$ Previous studies demonstrated the sensitization of pancreas-specific dorsal root ganglion (DRG) neurons and its involvement in abdominal pain in $\mathrm{CP}^{3,4}$ However, the detailed mechanisms of peripheral sensitization in $\mathrm{CP}$ remain largely unknown.

Under pathological conditions, a variety of small molecules, cytokines and enzymes can induce sensitization of sensory neurons, resulting in persistent pain. ${ }^{5-7}$ Transforming growth factor- $\beta 1$ (TGF- $\beta 1$ ) is also prominently expressed in such conditions and plays a central role in wound healing and promoting fibrosis in various diseases, including $\mathrm{CP}^{8-10}$ However, the role of TGF- $\beta 1$ in pain processing is controversial. Evidence suggests that TGF- $\beta 1$ has protective effects against neuropathic pain in the central nervous system, ${ }^{11,12}$ while in peripheral nervous system, TGF- $\beta 1$ is recently reported as an algogenic substance that contributes to peripheral sensitization by downregulation of the KCNA4 gene, ${ }^{13}$ or activation of cyclin-dependent kinase-transient receptor potential vanilloid type 1 (Cdk5-TRPV1) signaling ${ }^{14,15}$ and transforming growth factor $\beta$ activated kinase 1 (TAK1)/protein kinase $\mathrm{C}$ (PKC)-TRPV1 signaling. ${ }^{16}$ As mentioned in those studies, ${ }^{13-16}$ TGF- $\beta 1$ is a complex modulator of sensory neuronal function, and its signaling pathway in the induction and development of pancreatic pain in rats with chronic pancreatitis was not fully understood. Therefore, the roles of TGF- $\beta 1$ and its receptors were re-explored in the setting of chronic pancreatitis.

In the present study, we show that TGF- $\beta 1$ promptly excites primary sensory neurons and increases the concentration of intracellular calcium, both of which have not been reported before. Since TGF- $\beta 1$ is known to be upregulated in the pancreas in rodents as well as humans with $\mathrm{CP}^{17,18}$ we investigated the role of TGF- $\beta 1$ in the development of abdominal pain. We show that TGF- $\beta 1$ in vivo promptly induces mechanical hyperalgesia of the abdomen. TGF- $\beta 1$ and its receptors are up-regulated in pancreatic DRGs in $\mathrm{CP}$ rats. Blockade of this signaling attenuates mechanical hyperalgesia. Our results provide a novel mechanism underlying the involvement of TGF- $\beta 1$ in abdominal pain hypersensitivity.

\section{Materials and Methods}

\section{Animals}

Adult male Sprague-Dawley rats (200-220 g) were employed in the present study. Care and handling of rats were approved by the Institutional Animal Care and Use Committee of Soochow University. All experiments were performed in accordance with the guidelines of the International Association for the Study of Pain. Abdominal surgery was carried out under anesthesia of ketamine (80 mg/kg, intraperitoneal [i.p.]) plus xylazine (5-10 mg/kg, i.p.). Following tissue harvest, rats were sacrificed by decapitation.

\section{Induction of Chronic Pancreatitis in Rats}

Chronic pancreatitis (CP) was induced by an intraductal injection of trinitrobenzene sulfonic acid (TNBS), as described previously. ${ }^{3,4}$ Control rats received normal saline (NS). Further intervention and experiments in vivo or in vitro are performed at 3 weeks after TNBS treatment when a robust chronic pancreatitis had developed.

\section{Western Blotting}

Proteins were extracted from T9-T13 DRGs from control and $\mathrm{CP}$ rats as described previously. ${ }^{19,20}$ Protein extracts from DRGs or pancreas were loaded onto a $15 \%$ Tris-HCl SDS-PAGE gel (Bio-Rad, Hercules, CA, USA). After electrophoresis, proteins were electrotransferred onto $0.22 \mu \mathrm{m}$ polyvinyldifluoride membrane (Millipore, Billerica, MA, USA) at $200 \mathrm{~mA}$ for 2 hours at $4^{\circ} \mathrm{C}$. Primary antibodies used in the present study were mouse anti-TGF- $\beta 1$ (1:2000; Abcam ab27969, Cambridge, UK), rabbit anti-TGF- $\beta$ R I (1:200; Abcam ab31013), rabbit anti-TGF- $\beta$ R II (1:1000; Abcam ab186838), and rabbit anti-GAPDH or mouse anti- $\beta$-actin (1:1000; MultiSciences Biotech Co, Hangzhou, China). Mouse anti-TGF- $\beta 1$ can recognize both TGF- $\beta 1$ and latent TGF- $\beta 1$ complex. The same loading control, GAPDH, was used for analysis of both TGF- $\beta 1$ and latent TGF- $\beta 1$ complex (Fig. 1E and $1 \mathrm{~F}$ ). Secondary antibodies were horseradish peroxidase-conjugated goat anti-mouse or rabbit antibody (1:4000; MultiSciences Biotech $\mathrm{Co}_{\mathrm{o}}$. The immunoreactive proteins were detected by enhanced chemiluminescence (ECL kit; Amersham Biosciences, Arlington Heights, IL, USA). The membranes were 
A
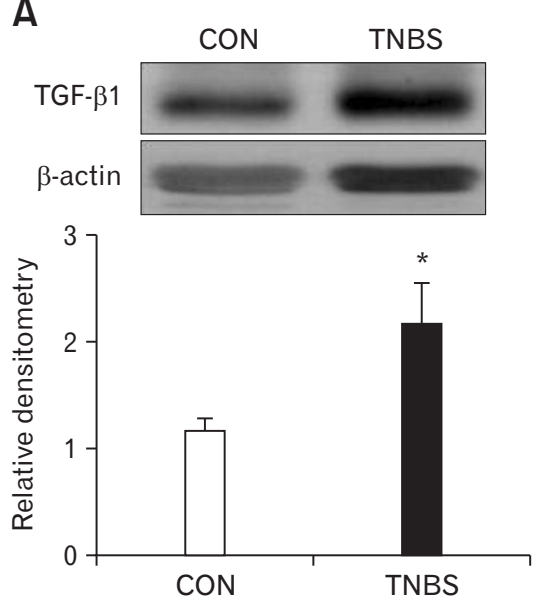

D

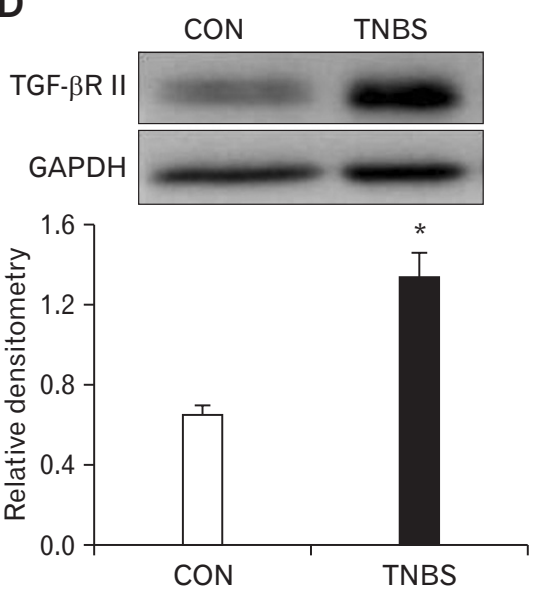

B
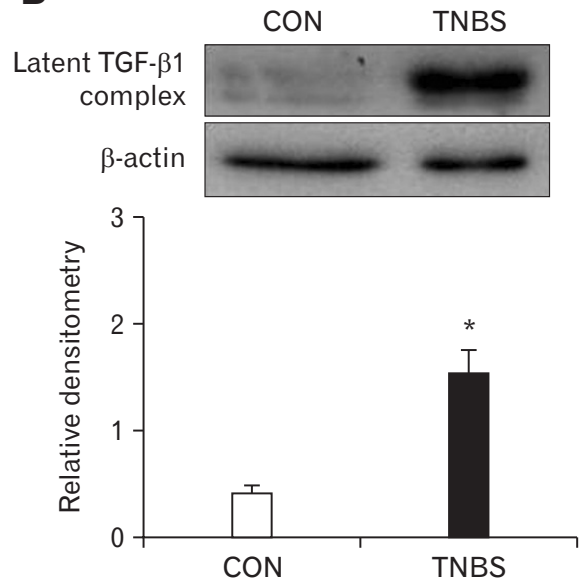

E
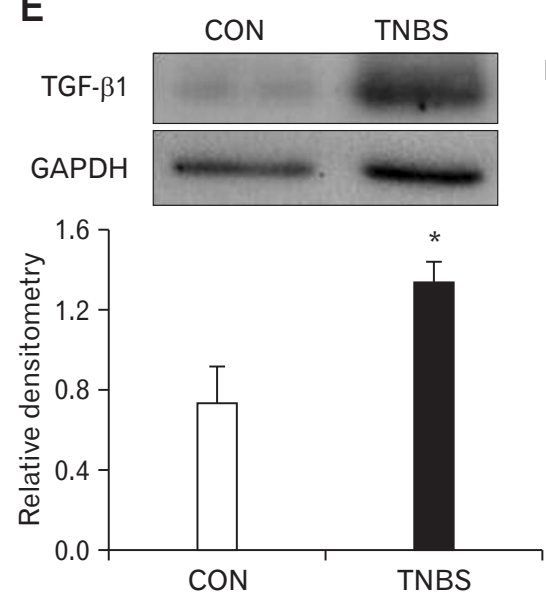

C
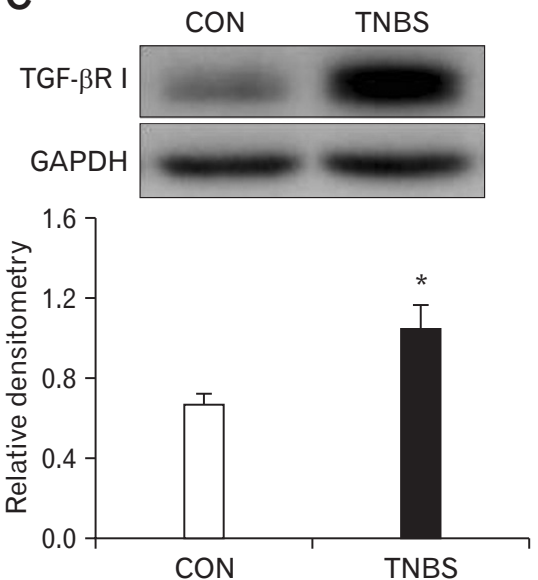

$\mathbf{F}$
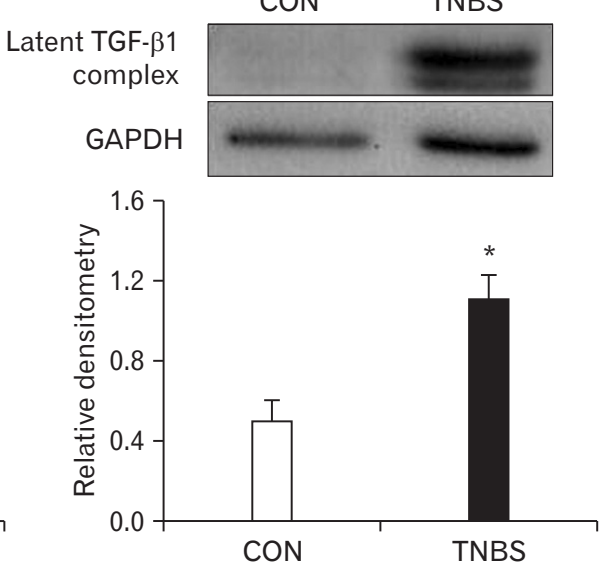

Figure 1. Trinitrobenzene sulfonic acid (TNBS) injection up-regulates expression of transforming growth factor- $\beta 1$ (TGF- $\beta 1$ ) and TGF- $\beta$ receptors. (A, B) TNBS injection significantly enhanced the expression of TGF- $\beta 1$ and latent TGF- $\beta 1$ complex in the pancreas of rats $\left({ }^{*} P<0.05\right.$, n $=4$ per group, two-sample $t$ test). (C-F) TNBS injection significantly enhanced the expression of TGF- $\beta$ receptor I and II, TGF- $\beta 1$, and latent TGF- $\beta 1$ complex in the pancreatic dorsal root ganglions (DRGs) of rats ( ${ }^{*} P<0.05, \mathrm{n}=4$ per group, two-sample $t$ test). CON, control.

scanned and bands were visualized by Bio-Rad ChemiDoc XRS+. Band intensities were measured by Image $\mathrm{J}$ software. All samples were normalized to GAPDH or $\beta$-actin as a loading control.

\section{Von Frey Filament Measurements}

Von Frey filament (VFF) testing was performed as described previously. ${ }^{4,20}$ The filament at the force of $10 \mathrm{~g}$ (North Coast Medial Inc, San Jose, CA, USA) was applied to the designated abdominal area 10 times each for 1-2 seconds, with a 10-second interval between applications. A response was considered positive when the rat raised its belly. All behavioral tests were performed in a blinded manner. Behavioral data were expressed as the number of positive responses per 10 times stimulation for each rat.

\section{Drug Application}

TGF- $\beta 1$ (PeproTech, Rocky Hill, NJ, USA) was dissolved in phosphate buffered saline (contain $0.1 \%$ bovine serum albumin) as stock solution, and freshly prepared diluted in normal external solution or $0.9 \%$ NS. TGF- $\beta$ receptor I antagonist, SB431542 (SigmaAldrich, St. Louis, MO, USA) was dissolved in dimethyl sulfoxide (DMSO) as stock solution, and freshly prepared in normal external solution or $0.9 \%$ NS. TRPV1 antagonist, capsazepine (CZP; Sigma-Aldrich) was dissolved in methanol as stock solution, and freshly prepared diluted in normal external solution. 


\section{Evaluation of Motor Performance}

The effects of SB431542 and TGF- $\beta 1$ on motor performance of rats were determined by the Rota-rod test as described previously. ${ }^{21}$ The length of time for rats to stay on the revolving bar (20 rpm) was recorded and analyzed.

\section{Labeling of Pancreas-specific Dorsal Root Ganglia Neurons}

For experiments involving calcium imaging and patch clamp recordings, the lipid-soluble fluorescence dye, 1,19-dioleyl-3, 3, 39, 3-tetramethy-lindocarbocyanine methanesulfonate (DiI; Invitrogen, Carlsbad, CA, USA), $25 \mathrm{mg}$ in $0.5 \mathrm{~mL}$ methanol, was injected in $1 \mu \mathrm{L}$ volume at 8-10 sites on the exposed pancreas under anesthesia, as described previously., Three weeks after Dil injection, DRGs (T9-T13) were dissected out for patch clamp recordings and calcium imaging study.

\section{Dissociation of Dorsal Root Ganglion Neurons}

Isolation of DRG neurons from adult rats was performed as described previously. ${ }^{3,422}$ In brief, bilateral T9-T13 DRGs were dissected out and incubated in dissecting solution containing collagenase $\mathrm{D}$ (1.5-1.8 mg/mL; Roche, Indianapolis, IN, USA) and tryp$\sin \left(1.2 \mathrm{mg} / \mathrm{mL}\right.$; Sigma-Aldrich) for 90 minutes at $34.5^{\circ} \mathrm{C}$. DRGs were then washed and transferred to the dissecting solution containing DNase (0.5 mg/mL; Sigma-Aldrich). A single cell suspension was obtained by repeated trituration through flame-polished glass pipettes. Cells were then plated onto acid-cleaned glass coverslips for patch-clamp recordings and calcium measurements.

\section{Patch-clamp Recordings}

As described previously, ${ }^{3,21}$ coverslips containing adherent DRG neurons were put in a chamber $(\sim 1 \mathrm{~mL}$ volume), attached to the stage of an inverting microscope (IX70 Olympus, Tokyo, Japan), and continuously superfused $(1.5 \mathrm{~mL} / \mathrm{min})$ at room temperature with normal external solution. ${ }^{3}$ Recording pipettes were pulled from the borosilicate glass tubing using a horizontal puller (P-97; Sutter Instruments, Novato, CA, USA) and typically had a resistance of 5-8 $\mathrm{M} \Omega$ when filled with normal pipette solution. ${ }^{3}$ Recordings were performed with an EPC10 amplifier and the program Patchmaster (HEKA Elektronik, Lambrecht, Germany).

\section{Intracellular Calcium Measurements}

Fura-2 $\mathrm{Ca}^{2+}$ imaging was performed as described previously. ${ }^{20}$ Recordings were performed by the program MetaFlour (Molecular
Device, Sunnyvale, CA, USA). The ratio of fluorescence signal measured at $340 \mathrm{~nm}$, divided by the fluorescence signal measured at $380 \mathrm{~nm}$, was used as an indicator for intracellular calcium mobilization. The percentage of changes in ratio was calculated to measure the drug-induced calcium mobilization.

\section{Statistical Methods}

All data in the present study were expressed as mean \pm SEM or as a percentage. Statistical analyses were conducted using OriginPro 8 (OriginLab, Northampton, MA, USA). Normality of all data was checked before analyses. Significance of difference was determined by two-sample or paired sample $t$ test, one-way repeated measures ANOVA followed by Tukey post hoc test, or two-way ANOVA followed by Tukey post hoc test. A $P$-value $<0.05$ was considered statistically significant.

\section{Results}

\section{TNBS Injection Up-regulates Expression of Trans- forming Growth Factor- $\beta 1$ and Transforming Growth Factor- $\beta$ Receptors}

Three weeks after TNBS injection, the expression of TGF- $\beta 1$ and latent TGF- $\beta 1$ complex (TGF- $\beta 1$ precursor) in pancreas of rats were significantly increased $\left({ }^{\star} P<0.05\right.$ versus control; $\mathrm{n}=$ 4 per group; Fig. 1A and 1B), consistent with clinical features of patients with $\mathrm{CP}$ described previously. ${ }^{17}$ We further examined the expression of TGF- $\beta 1$ and its receptors in pancreatic DRGs (T9T13) from control and TNBS-treated rats. The expression of TGF- $\beta 1$, latent TGF- $\beta 1$ complex, and TGF- $\beta$ receptor I and II in pancreatic DRGs were significantly increased $\left({ }^{\star} P<0.05\right.$ versus control; $\mathrm{n}=4$ per group; Fig. $1 \mathrm{C}-\mathrm{F}$ ). These data suggest that TNBS injection leads to up-regulation of TGF- $\beta 1$ and its receptors in peripheral nervous system, which implicates the possible activation of TGF- $\beta 1$ /TGF- $\beta$ receptors signaling in pancreatic DRGs of $\mathrm{CP}$ rats.

\section{Transforming Growth Factor- $\beta$ Receptor I Antagonist Attenuates Mechanical Hyperalgesia}

Single intrathecal injection (i.t.) of SB431542, a specific and potent TGF- $\beta$ receptor I antagonist, significantly reduced the response frequency to stimulation force of $10 \mathrm{~g}$ compared with the NS group in a dose-dependent manner ${ }^{* *} P<0.01$, ${ }^{* *} P<$ 0.001 versus NS; $n=7$ per group; Fig. $2 A$ ). The optimized dose of the maximal inhibition effect was $100 \mu \mathrm{g} / \mathrm{kg}$ body weight $(P$ 
A
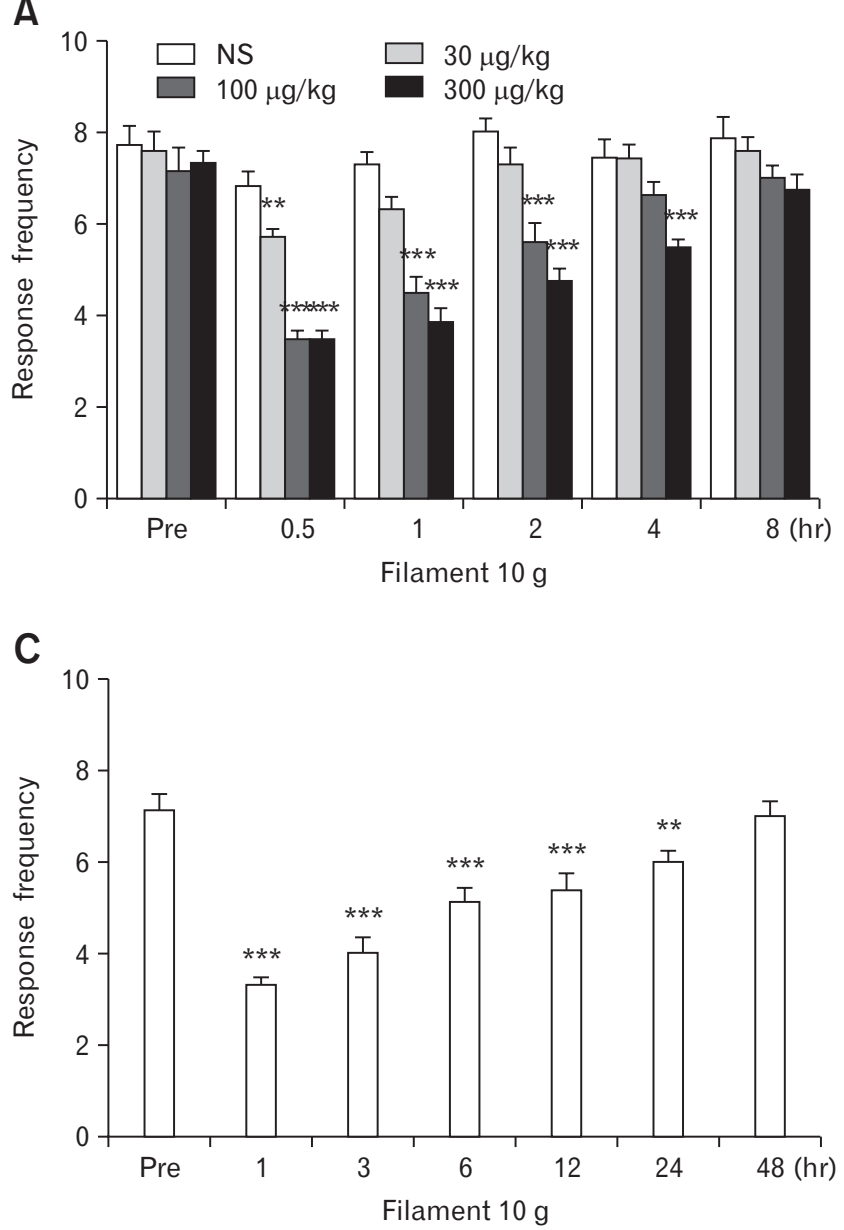

B

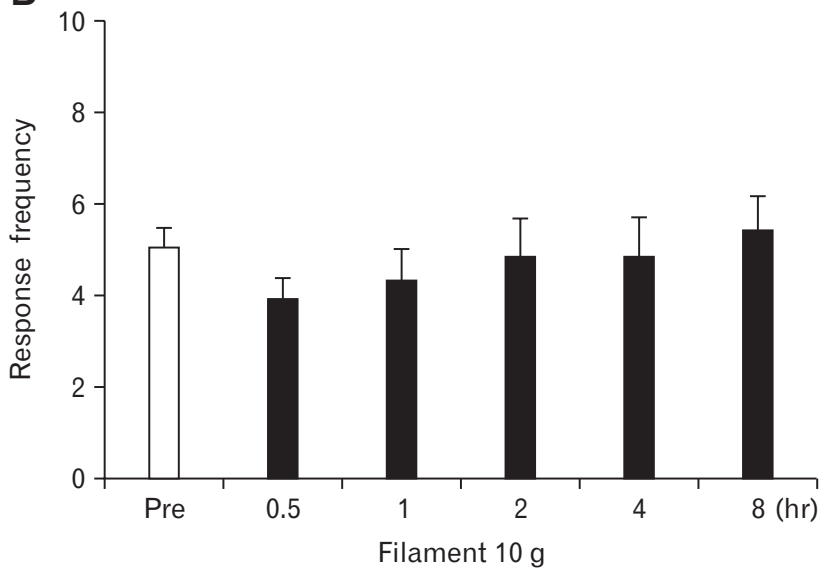

D

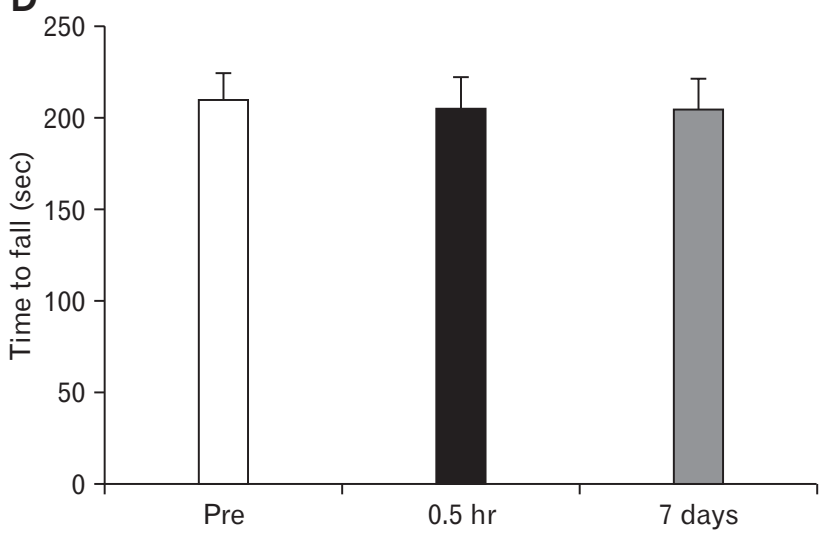

Figure 2. Transforming growth factor- $\beta$ (TGF- $\beta$ ) receptor I antagonist SB431542 attenuates mechanical hyperalgesia. (A) Intrathecal injection (i.t.) of SB431542 significantly reduced response frequency of chronic pancreatitis (CP) rats to von Frey filament $(\mathrm{VFF})$ stimuli $(10 \mathrm{~g})(* * P<0.01$, ${ }^{* *} \mathrm{P}<0.001$ versus normal saline [NS]; $\mathrm{n}=7$ per group). (B) SB431542 at $100 \mu \mathrm{g} / \mathrm{kg}$ (i.t.) had no significant effect on response frequency of control rats $(\mathrm{n}=7)$. (C) Daily intrathecal injection of SB431542 at $100 \mu \mathrm{g} / \mathrm{kg}$ for 7 days significantly reduced the response frequency of CP rats, which last for 24 hours $\left({ }^{* *} P<0.01\right.$, ${ }^{* *} P<0.001$ versus Pre [before administration]; n $=7$ ). (D) SB431542 at $100 \mu \mathrm{g} / \mathrm{kg}$ (i.t.) did not produce any effect on time for the $\mathrm{CP}$ rats to stay on the rotation bar $(n=8)$. Paired sample $t$ test $(\mathrm{B}-\mathrm{D})$, two-way ANOVA followed by Tukey post hoc test (A).

$>0.05,300 \mu \mathrm{g} / \mathrm{kg}$ versus $100 \mu \mathrm{g} / \mathrm{kg}$ ), which lasted for 2 hours. Thus, we used this dose in age-matched healthy rats to determine the drug specificity. SB431542 at a dose of $100 \mu \mathrm{g} / \mathrm{kg}$ had no significant effect on response frequency in healthy rats, indicating that SB431542 is not a nonspecific analgesic (compared with Pre [before administration], $\mathrm{n}=7$; Fig. 2B) and exerts its effect on behavior only in CP rats. Furthermore, SB431542 at $100 \mu \mathrm{g} / \mathrm{kg}$ was administered intrathecally once daily for 7 consecutive days in $\mathrm{CP}$ rats. As expected, multiple injections of SB431542 produced a dramatic antinocifensive effect in $\mathrm{CP}$ rats, lasting for at least 24 hours $(* * P$ $<0.01,{ }^{\star \star *} P<0.001$ versus Pre; $\mathrm{n}=7$; Fig. $2 \mathrm{C}$ ). To exclude the possible effect of SB431542 on motor performance, the Rotarod test was performed. Neither single nor multiple injections of SB431542 at $100 \mu \mathrm{g} / \mathrm{kg}$ altered the time for rats to stay on the rotation bar compared with Pre $(\mathrm{n}=8$; Fig. 2D). These data suggest that TGF- $\beta 1 / \mathrm{TGF}-\beta$ receptor signaling is involved in mechanical hyperalgesia of abdomen in $\mathrm{CP}$.

\section{Transforming Growth Factor- $\beta 1$ Produces Mechani- cal Hyperalgesia}

To determine whether TGF- $\beta 1$ produces hyperalgesia, TGF- $\beta 1$ was injected intrathecally in healthy rats. Administration 


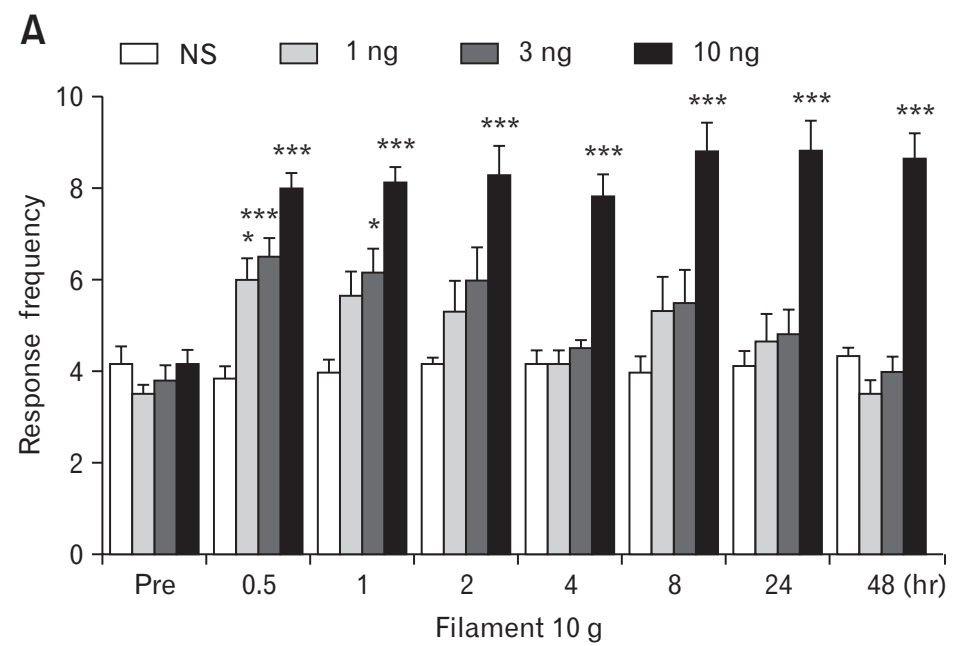

B

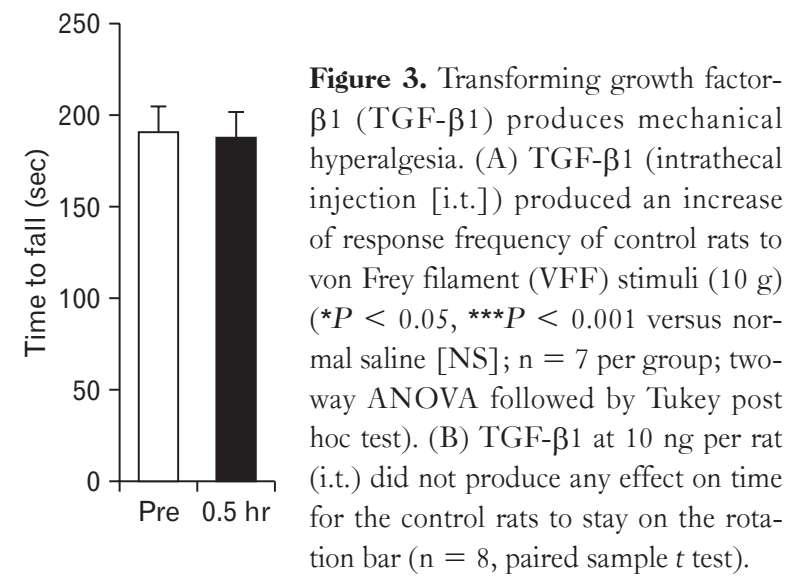

of TGF- $\beta 1$ produced an increase in response frequency to stimulation force of $10 \mathrm{~g}$ compared with NS controls in a dose-dependent manner $\left({ }^{\star} P<0.05,{ }^{* * *} P<0.001\right.$ versus NS; $\mathrm{n}=7$ per group; Fig. 3A). The maximal hyperalgesic effect was observed at a dose of $10 \mathrm{ng}$ per rat. The effect produced by 1 and $3 \mathrm{ng}$ per rat TGF- $\beta 1$ lasted for 0.5 and 1 hours, respectively (Fig. 3A). Interestingly, the effect produced by $10 \mathrm{ng}$ per rat TGF- $\beta 1$ last for at least 48 hours. However, Rota-rod test shows TGF- $\beta 1$ at $10 \mathrm{ng}$ per rat did not alter the time for rats to stay on the rotation bar compared with Pre (n $=8$; Fig. $3 \mathrm{~B}$ ).

\section{Transforming Growth Factor- $\beta 1$ Induces Depolarization or Firing Activity of Dorsal Root Ganglion Neurons}

In order to investigate the potential role of TGF- $\beta 1$ in the activation of peripheral nociceptors, electrophysiological recordings were performed on small and medium-size DRG neurons that are likely to mediate nociception and pain. ${ }^{23,24}$ In our study, Dil-labeled pancreas-specific DRG neurons were recorded (Fig. 4A). Under whole-cell current clamp recordings, bath application of $10 \mathrm{ng} /$ $\mathrm{mL}$ TGF- $\beta 1$ depolarized the resting membrane potential (RP) in a portion of DRG neurons (34 out of 55 neurons recorded; Fig. $4 \mathrm{~B}$ and $4 \mathrm{C})$. The $\mathrm{RP}$ returned to the baseline within 1 minute after washout. Sixteen of these 34 neurons exhibited action potentials (APs) after TGF- $\beta 1$ application (16 out of 55 neurons recorded; Fig. 4B and 4C). For the remaining 18 activated neurons without firings, the average amplitude of depolarization was $5.9 \pm 1.2 \mathrm{mV}$ (Fig. 4D). The other 21 neurons showed no response to TGF- $\beta 1$ application (Fig. 4B and 4C).

\section{Transforming Growth Factor- $\beta 1$ Enhances Excitability of Dorsal Root Ganglion Neurons}

As the above results suggest that TGF- $\beta 1$ depolarized the $\mathrm{RP}$ in a portion of DRG neurons, we then examined the effect of TGF- $\beta 1$ (10 ng/mL, bath application for 3 minutes) on provoked excitability of DRG neurons. Rheobase, the minimal stimulation current to evoke APs, was significantly decreased after TGF- $\beta 1$ application (Pre: 103.2 $\pm 15.8 \mathrm{pA}$, Post: $87.4 \pm 14.1 \mathrm{pA}$; ${ }^{*} P<0.05$; $\mathrm{n}=19$; Fig. 5A). The AP threshold, the minimal voltage at which the AP was generated, was markedly decreased after TGF- $\beta 1$ application (Pre: $-29.7 \pm 0.9 \mathrm{mV}$, Post: $-33.3 \pm 0.9 \mathrm{mV}$; ${ }^{* *} P<$ $0.01 ; \mathrm{n}=19$; Fig. $5 \mathrm{~B}$ ). In addition, application of TGF- $\beta 1$ also increased the number of APs evoked by 300-milliseconds 2 times $(2 \times)$ and 3 times $(3 \times)$ rheobase current stimulation $(2 \times$, Pre: 4.84 \pm 0.24 , Post: $5.79 \pm 0.44,{ }^{*} P<0.05, \mathrm{n}=19 ; 3 \times$, Pre: $8.00 \pm$ 0.31, Post: $9.26 \pm 0.58,{ }^{*} P<0.01, \mathrm{n}=19$; Fig. $5 \mathrm{C}$ and $5 \mathrm{D}$ ). Furthermore, application of TGF- $\beta 1$ significantly increased the number of APs evoked by 1-second ramp current stimulation from 0 to $200 \mathrm{pA}$ or $500 \mathrm{pA}$ (200 pA ramp, Pre: $2.84 \pm 0.61$, Post: 4.26 $\pm 0.76,{ }^{*} \mathrm{P}<0.01, \mathrm{n}=19 ; 500 \mathrm{pA}$ ramp, Pre: $6.32 \pm 0.85$ Post: $7.89 \pm 0.96,{ }^{* *} P<0.01, \mathrm{n}=19$; Fig. $5 \mathrm{E}$ and $5 \mathrm{~F}$ ). These results suggest that TGF- $\beta 1$ treatment promptly enhances the excitability of pancreas-specific DRG neurons.

Transforming Growth Factor- $\beta 1$ Increases Intracellular Calcium lon Concentration via Transforming Growth Factor- $\beta$ Receptor I in Dorsal Root Ganglion Neurons

We then studied the acute effect of TGF- $\beta 1$ on intracellular calcium mobilization of DRG neurons. Bath application of $10 \mathrm{ng} /$ 
A
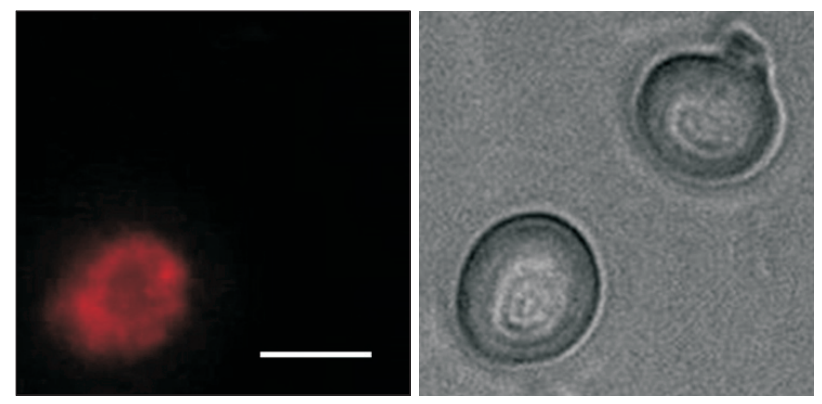

B

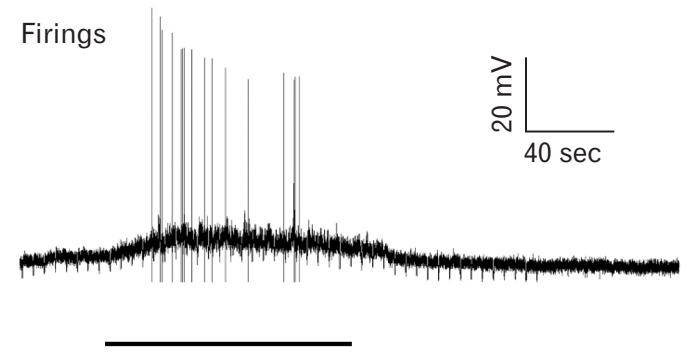

Depolarization

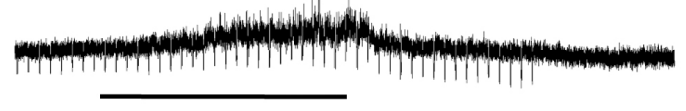

No response
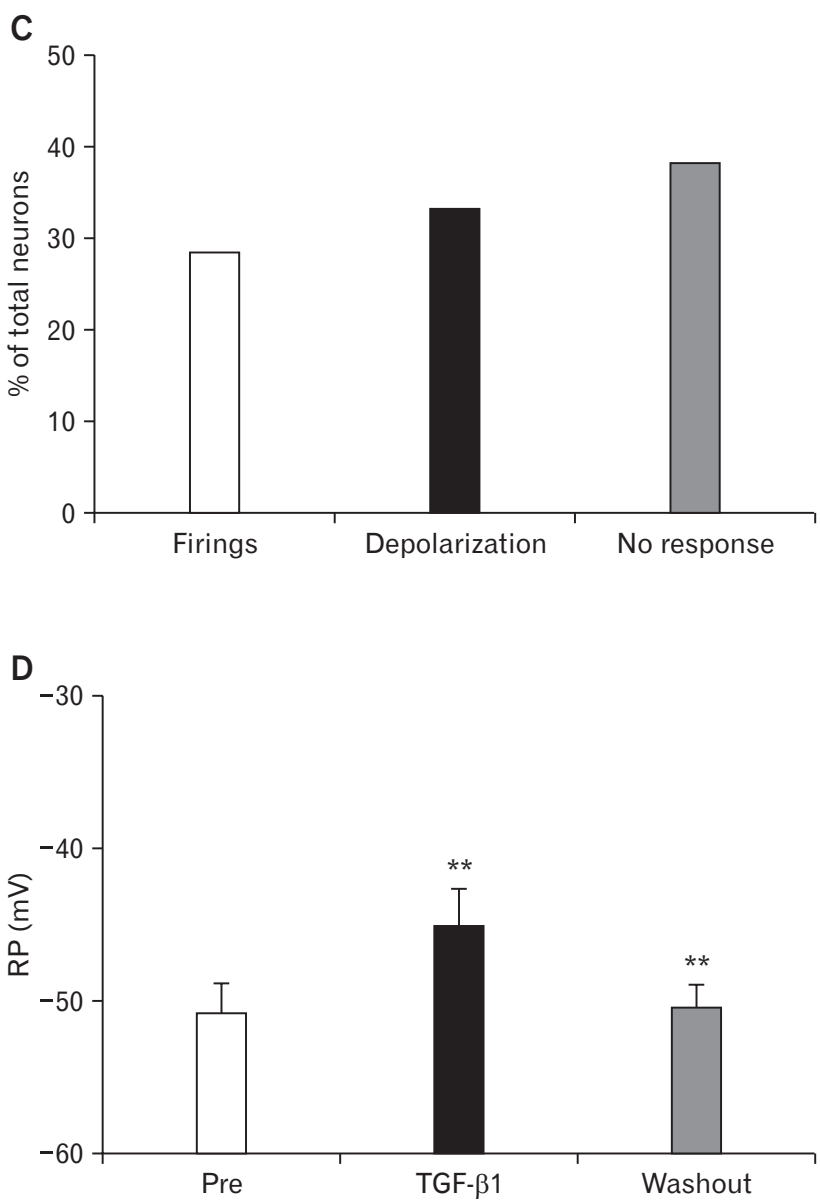

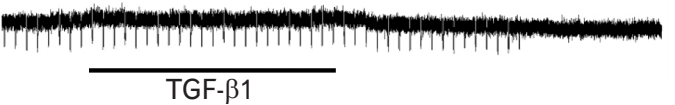

Figure 4. Transforming growth factor- $\beta 1$ (TGF- $\beta 1$ ) induces depolarization and firing activity of dorsal root ganglion (DRG) neurons. (A) DiIfluorescence (left) and bright-field (right) images of acutely isolated DRG neurons. Pancreas-specific neurons are shown in red in DiI-fluorescence image. Bar $=25 \mu \mathrm{m}$. (B) The typical current-clamp recordings of DRG neurons showing firings, depolarization or no response after application of $10 \mathrm{ng} / \mathrm{mL}$ TGF- $\beta 1$. (C) The percentage of DRG neurons showing firings (28.6\%), depolarization (33.3\%), or no response (38.1\%) after application of TGF- $\beta 1$ ( $n=55$ neurons in total). (D) Resting membrane potentials (RPs) before TGF- $\beta 1$ application (Pre), peak value of RPs during TGF- $\beta 1$ application (TGF- $\beta 1$ ) and RPs after washout (Washout) $\left({ }^{* *} P<0.01\right.$ for TGF- $\beta 1$ versus Pre, and Washout versus TGF- $\beta 1$; $n=18$; one-way repeated measures ANOVA followed by Tukey post hoc test).

$\mathrm{mL}$ TGF- $\beta 1$ for 1 minute caused significant intracellular calcium ion concentration $\left(\left[\mathrm{Ca}^{2+}\right]_{\mathrm{i}}\right)$ increase in a portion of DRG neurons (32 of 114 neurons recorded; Fig. 6A). The average magnitude of TGF- $\beta 1$-induced $\left[\mathrm{Ca}^{2+}\right]_{\mathrm{i}}$ increase was $36.4 \pm 6.0 \%(\mathrm{n}=32$; Fig. $6 \mathrm{~A})$. The $\left[\mathrm{Ca}^{2+}\right]_{\mathrm{i}}$ returned to baseline within 1 minute after washout in most neurons tested. When TGF- $\beta 1$ was applied twice at an interval of 10 minutes, the magnitude of the second $\left[\mathrm{Ca}^{2+}\right]_{i}$ increase was $33.7 \pm 7.0 \%$, which was not significantly different from that of the first amplitude ( $\mathrm{n}=32$; Fig. $6 \mathrm{~A})$, suggesting that no desensiti- zation occurs during repetitive application of TGF- $\beta 1$.

To examine whether TGF- $\beta$ receptor I was involved in the TGF- $\beta 1$-evoked $\left[\mathrm{Ca}^{2+}\right]_{\mathrm{i}}$ increase, DRG neurons were pretreated with SB431542 (10 $\mu \mathrm{M}, 3$ minutes). In the presence of SB431542, the $\left[\mathrm{Ca}^{2+}\right]_{\mathrm{i}}$ increase evoked by TGF- $\beta 1$ was significantly less than that in the control medium ( ${ }^{* *} P<0.001$ versus Pre, $n=43$; Fig. 6B). The inhibitory effect of SB431542 on the $\left[\mathrm{Ca}^{2+}\right]_{\mathrm{i}}$ increase was partly reversed after 10 minute washings ( $P<0.05$ versus SB431542, $n=43$; Fig. 6B). Since previous reports revealed that 
A

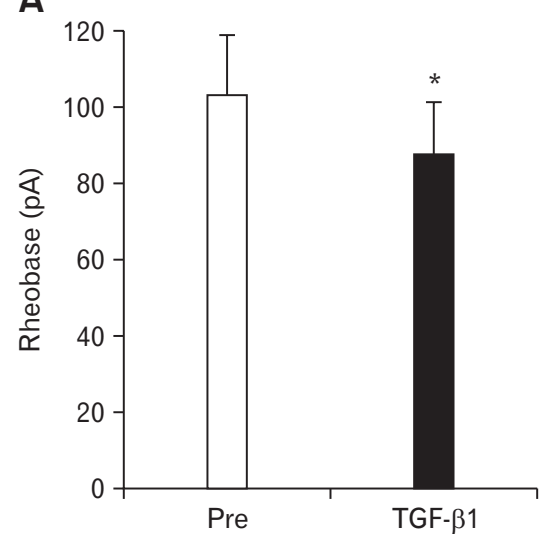

C

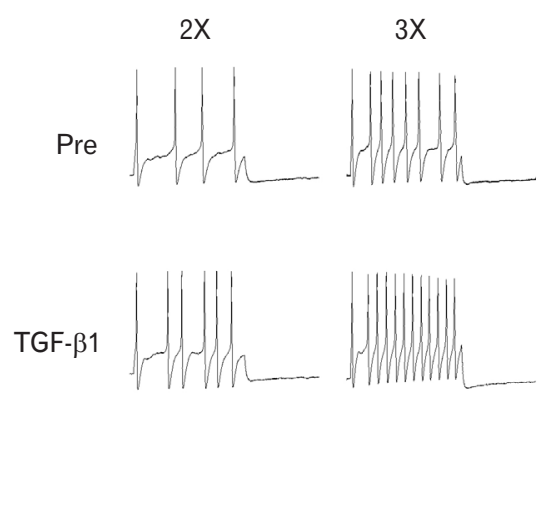

E

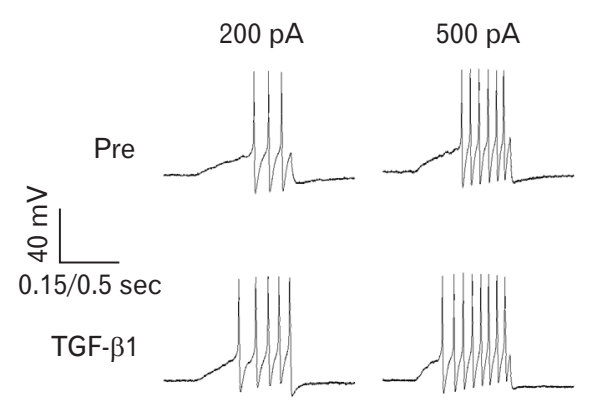

B

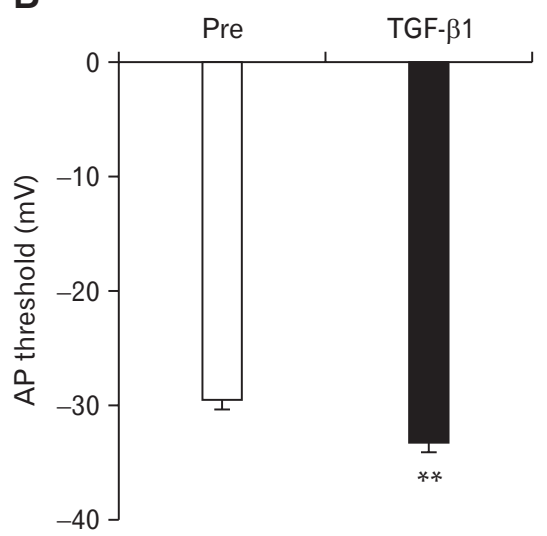

D

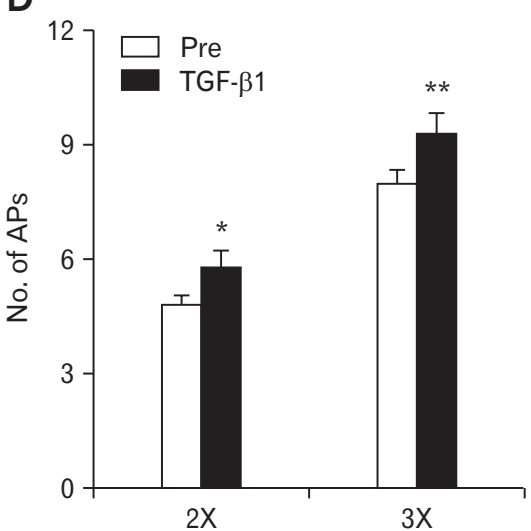

$\mathbf{F}$

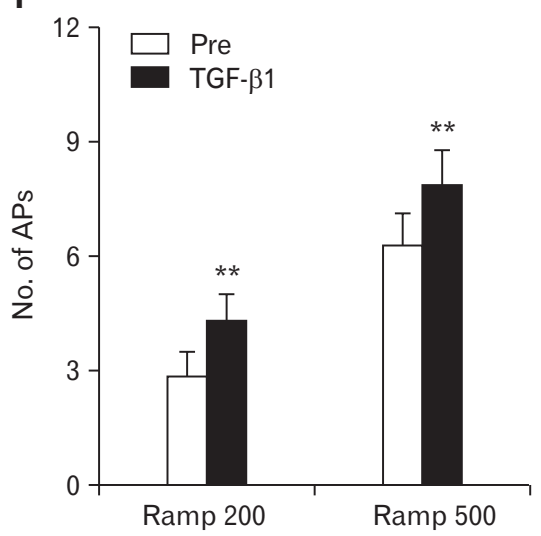

Figure 5. Transforming growth factor- $\beta 1$ (TGF- $\beta 1$ ) enhances excitability of dorsal root ganglion neurons. (A) TGF- $\beta 1$ application significantly reduced rheobase $\left({ }^{\star} P<0.05, \mathrm{n}=19\right)$. (B) TGF- $\beta 1$ application markedly decreased action potential (AP) threshold $\left({ }^{\star *} P<0.01, \mathrm{n}=19\right)$. (C) Typical traces of APs evoked by 2 times $(2 \times)$ and 3 times $(3 \times)$ rheobase current stimulation. (D) Bar graph shows the numbers of APs evoked by $2 \times$ and $3 \times$ rheobase current stimulation were significantly increased after TGF- $\beta 1$ application $\left({ }^{*} P<0.05,{ }^{*} P<0.01\right.$; $\left.\mathrm{n}=19\right)$. (E) Typical traces of APs evoked by $200 \mathrm{pA}$ and $500 \mathrm{pA}$ ramp current stimulation. (F) Bar graph shows the numbers of AP evoked by $200 \mathrm{pA}$ and 500 pA ramp current stimulation were significantly increased after TGF- $\beta 1$ application $(* * P<0.01, \mathrm{n}=19)$. Paired sample $t$ test (A-F). Pre, before TGF- $\beta 1$ application.

TGF- $\beta 1$ sensitizes TRPV1 in DRG neurons ${ }^{14,16,25}$ we next examined whether TRPV1 was involved in the TGF- $\beta 1$-induced $\left[\mathrm{Ca}^{2+}\right]$ i increase. Pretreatment with TRPV1 antagonist CZP $(10 \mu \mathrm{M}, 3$ minutes) did not alter the magnitude of TGF- $\beta 1$-evoked $\left[\mathrm{Ca}^{2+}\right]_{\mathrm{i}}$ increase (Fig. $6 \mathrm{C}, \mathrm{n}=28$ ), suggesting that TGF- $\beta 1$-evoked $\left[\mathrm{Ca}^{2+}\right]_{\mathrm{i}}$ increase is not mediated by TRPV1.

\section{Discussion}

The present study demonstrated that TGF- $\beta 1$ and its receptors are involved in the mechanical hyperalgesia of abdomen in rats with chronic pancreatitis (CP). It is well known that TGF- $\beta 1$ is upregulated in the pancreas of rodents as well as patients with $\mathrm{CP}^{17,18}$, and plays a dominant role in the development of $\mathrm{CP}$ by contributing to local inflammation and promoting pancreatic fibrosis. ${ }^{10,18,26}$ In addition to upregulation of TGF- $\beta 1$ expression in the pancreas of TNBS-treated rats, we furthermore showed that TGF- $\beta 1$ and it receptors were also up-regulated in pancreatic DRGs of CP rats, which implicated that TGF- $\beta 1 /$ TGF- $\beta$ receptor signaling might be also activated in the peripheral nervous system in $\mathrm{CP}$ rats. A recent report shows that administration of TGF- $\beta 1$ neutralizing antibody significantly attenuated the pancreatic hyperalgesia in rats with $\mathrm{CP}^{13}$ In the present study, administration of SB431542, a potent and selective TGF- $\beta$ receptor I antagonist, ${ }^{27}$ significantly attenuated mechanical hyperalgesia of abdomen in CP rats. Together, these data suggest a role for TGF- $\beta 1$ and its receptors in the develop- 
A

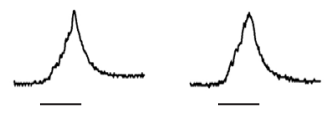

1st TGF- $\beta 1 \quad$ 2nd TGF- $\beta 1$

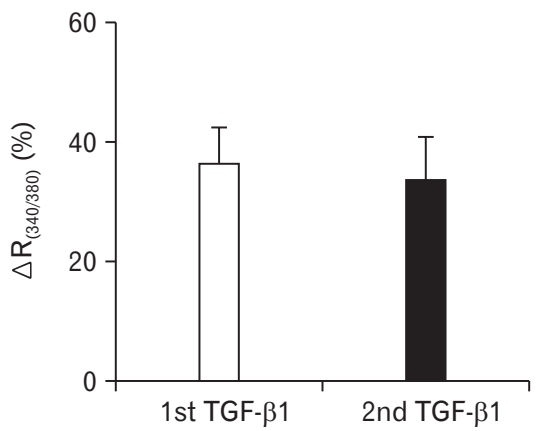

B

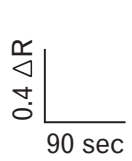

$\mathrm{sec}$

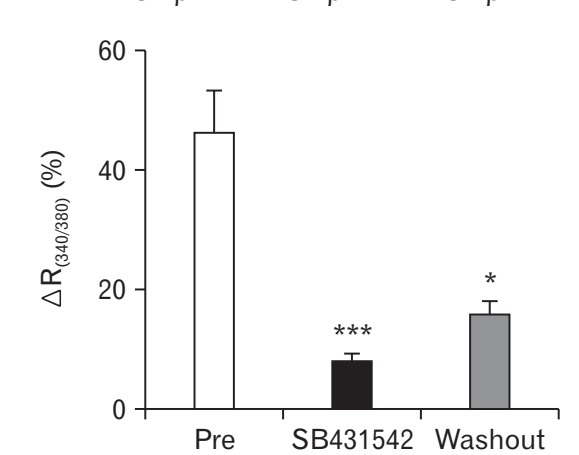

C

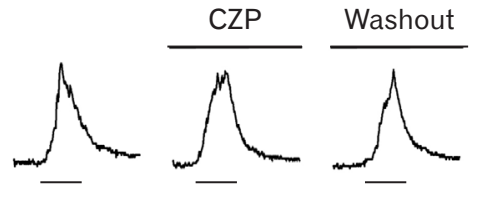

TGF- $\beta 1$

TGF- $\beta 1$

TGF- $\beta 1$

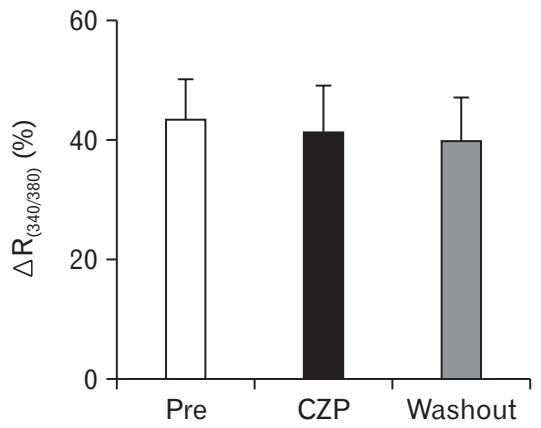

Figure 6. Transforming growth factor- $\beta 1$ (TGF- $\beta 1$ ) increases intracellular calcium ion concentration ( $\left.\left[\mathrm{Ca}^{2+}\right]_{\mathrm{i}}\right)$ via TGF- $\beta$ receptor I. (A) Representative traces of changes in $\left[\mathrm{Ca}^{2+}\right]_{\mathrm{i}}\left(\mathrm{R}_{(340 / 380)}\right)$ in dorsal root ganglion neurons induced by $10 \mathrm{ng} / \mathrm{mL}$ TGF- $\beta 1$ (top) and bar graph (bottom) shows no desensitization of TGF- $\beta 1$-evokded $\left[\mathrm{Ca}^{2+}\right]_{\mathrm{i}}$ increase after the second time application with an interval of 10 minutes (n = 32). (B) Representative traces of the inhibitory effect of TGF- $\beta$ receptor I antagonist, SB431542, at the dose of $10 \mu \mathrm{M}$ on TGF- $\beta 1$-evoked $\left[\mathrm{Ca}^{2+}\right]_{\mathrm{i}}$ increase. Bar graph shows SB431542 inhibited $80 \%$ of TGF- $\beta 1$-evoked $\left[\mathrm{Ca}^{2+}\right]_{\mathrm{i}}$ increase, which was partly reversed after washout $(* * * P<0.001$ versus Pre, ${ }^{*} P<0.05$ versus SB431542; $\mathrm{n}=43$ ). (C) Representative traces (top) and bar graph (bottom) show capsazepine $(\mathrm{CZP})$ at the dose of $10 \mu \mathrm{M}$ did not alter the TGF- $\beta 1$-evoked $\left[\mathrm{Ca}^{2+}\right]_{\mathrm{i}}$ increase $(\mathrm{n}=28)$. One-way repeated measures ANOVA followed by Tukey post hoc test (A-C). Pre, before SB431542 or CZP application; Washout, after washout.

ment of abdominal hyperalgesia in rats with $\mathrm{CP}$. Of particular note is that SB431542 did not affect nociceptive behaviors in control rats in our study, while in the previous report, ${ }^{13}$ TGF- $\beta 1$ neutralization in control rats resulted in pancreatic hyperalgesia. This discrepancy may be due to differences in the administration methods (intrathecal vs intraperitoneal) and in the focus on action time of the drugs (0.58 hours after injection vs 1 week after injection), or more probably due to the fact that we used the TGF- $\beta$ receptor I antagonist which blocks the TGF- $\beta$ signaling including TGF- $\beta 1$, TGF- $\beta 2$ and TGF- $\beta 3,{ }^{27-29}$ while TGF- $\beta 1$ neutralizing antibody does not block the other 2 isoforms (TGF- $\beta 2$ and TGF- $\beta 3$ ) that can also bind to TGF- $\beta$ receptors and further activate the downstream signaling.

Another important finding is that TGF- $\beta 1$ plays an acute effect on neuronal excitability. To the best of our knowledge, this is the first report that shows the acute effect of TGF- $\beta 1$ on neuron excitability. This is supported by the following observations. First, TGF- $\beta 1$ application depolarized the membrane potential and caused firing activity of pancreas-specific DRG neurons. Second, TGF- $\beta 1$ application also reduced the rheobase, hyperpolarized action potential threshold, and increased the number of action potentials evoked by current injection of pancreas-specific DRG neurons. In a previous report ${ }^{13}$ TGF- $\beta 1$ sensitization of DRG neurons in vitro, occurring after incubation of TGF- $\beta 1$ for 24 hours but not earlier ( 1 hour), was attributed to downregulation of the Kv1.4 gene and decreased voltage-gated A-type $\mathrm{K}^{+}$currents $\left(\mathrm{I}_{\mathrm{A}}\right)$, while TGF- $\beta 1$ sensitization in our study, occurring after application of TGF- $\beta 1$ for 3 minutes, was accompanied by decreased AP duration (data not shown), suggesting that the acute sensitized effect of TGF- $\beta 1$ was due to some factors other than Kv1.4. Although these factors remain to be further investigated, one possibility is that 2-pore domain potassium channels are the effectors in this pathway because inhibition of their activity leads to membrane depolarization ${ }^{30}$ similar to that observed in our study. This pathway mediates an immediate but mild depolarization that is not enough to trigger discharges.

In addition to enhancing the neuronal excitability, TGF- $\beta 1$ quickly increased $\left[\mathrm{Ca}^{2+}\right]_{\mathrm{i}}$ in pancreas-specific DRG neurons. Pretreatment of SB431542 largely inhibited or even completely blocked TGF- $\beta 1$-induced $\left[\mathrm{Ca}^{2+}\right]_{\mathrm{i}}$ increase, indicating the involvement of TGF- $\beta$ receptor I. Since TGF- $\beta$ receptors (I and II) are serinethreonine kinase receptors that cannot act as ion channels, ${ }^{31}$ downstream signaling and effectors are definitely necessary for TGF$\beta 1$-induced $\left[\mathrm{Ca}^{2+}\right]_{\mathrm{i}}$ increase. Recent studies indicate that TGF- $\beta 1$ 
signaling sensitizes TRPV1 in primary sensory neurons. ${ }^{14-16}$ However, our result suggests that TGF- $\beta 1$-induced $\left[\mathrm{Ca}^{2+}\right]_{\mathrm{i}}$ increase was independent of TRPV1. Of special note is that the proportion (16 of 55 neurons) of neurons displaying TGF- $\beta 1$-induced firing is very similar to the proportion (32 of 114 neurons) of neurons showing $\left[\mathrm{Ca}^{2+}\right]_{\mathrm{i}}$ increase to TGF- $\beta 1$, suggesting that TGF- $\beta 1$ induced $\left[\mathrm{Ca}^{2+}\right]_{i}$ increase might be due to the extracellular calcium influx through voltage-gated calcium channels (VGCCs). Nevertheless, our preliminary experiments show that neither pretreatment of $\mathrm{CdCl}_{2}$ (a none selective VGCC antagonist) nor removal of the extracellular calcium inhibited TGF- $\beta 1$-induced $\left[\mathrm{Ca}^{2+}\right]_{\mathrm{i}}$ increase (data not shown), suggesting that calcium release from intracellular calcium pools might be a main source of TGF- $\beta 1$-induced $\left[\mathrm{Ca}^{2+}\right]_{\mathrm{i}}$ increase. Thus, another possibility mediating the acute effects of TGF- $\beta 1$ is that calcium released from intracellular calcium pools as a second message opens one or more non-selective cation channels in direct or indirect ways, thus resulting in robust depolarization and discharges.

Although the detailed mechanisms have yet to be investigated, administration of TGF- $\beta 1$ induced mechanical hyperalgesia doseand time- dependently in healthy rats, confirming the involvement of acute effects of TGF- $\beta 1$ in pancreatic nociception. Surprisingly, a single administration of TGF- $\beta 1$ at a high dose produced a persistent algogenic effect lasting for at least 48 hours. It is possible that excessive TGF- $\beta 1$ may trigger some chronic effects. Our study does not exclude the importance of chronic effects of TGF- $\beta 1$ in peripheral sensitization. Acute effects may be an initiating event and accumulation of acute effects probably contributes to the occurrence and development of chronic effects, and in return, the chronic effects may amplify acute effects. Although the detailed mechanisms by which the acute effects of TGF- $\beta 1$ leads to chronic pain are unknown, we propose that the acute effects of TGF- $\beta 1$ might contribute to chronic pain in at least 2 ways. Firstly, TGF- $\beta 1$ causes discharges and increases the intracellular calcium in DRG neurons. As a second message, Calcium ions may trigger many cascade signal responses and further influences gene transcription or phosphorylation of kinases and receptors. In the present study, this acute effect may lead to the upregulation of TGF- $\beta 1$ / TGF- $\beta$ receptors in DRGs of the CP model. Secondly, since the expression of TGF- $\beta 1 /$ TGF- $\beta$ is increased, we hypothesize that the acute excitatory effects of TGF- $\beta 1$ may be amplified and thus cause more discharges and more calcium increase in DRG neurons of the CP model. It is possible that the acute effects of TGF- $\beta 1$ at normal level is not enough to trigger mechanical hyperalgesia in vivo, whereas the acute effects of TGF- $\beta 1$ under pathophysiologi- cal conditions may cause mechanical hyperalgesia and contribute to chronic pain in CP model. This hypothesis is supported by our results that SB431542 attenuates mechanical hyperalgesia in CP rats but has no effect on responses in healthy rats. Further studies are needed to test the detailed signaling pathways of TGF- $\beta 1$ effect in the animal model of chronic pancreatitis. The origin of TGF- $\beta 1$ might be from mononuclear cells located in the fibrotic areas and ducts damaged by fibrosis in the pancreas of $\mathrm{CP}$ patients. ${ }^{17}$

In summary, our study demonstrated for the first time that TGF- $\beta 1$ plays an acute effect on neuronal excitability, which might contribute to the mechanical hyperalgesia of abdomen in rats with chronic pancreatitis.

Financial support: This work was supported by grants from the National Natural Science Foundation of China (81230024, 81471137, and 31271258) and Priority Academic Program Development of Jiangsu Higher Education Institutions (PAPD). This project is subject to funding from the preponderant clinic group project of the Second Affiliated Hospital of Soochow University (XKQ2015008). The funders had no role in the study design, data collection and analysis, decision to publish, or preparation of the manuscript.

\section{Conflicts of interest: None.}

Author contributions: Xiaoyu Zhang: performed experiments, analyzed data, prepared figures, and drafted the manuscript; Hang Zheng: performed experiments, analyzed data, and drafted the manuscript; Hong-Yan Zhu: performed experiments and analyzed data; Shufen Hu: performed experiments, analyzed data, and prepared figures; Shusheng Wang: analyzed data; Xinghong Jiang: analyzed data and edited manuscript; and Guang-Yin Xu: designed and supervised the experiments and edited the manuscript.

\section{References}

1. Warshaw AL, Banks PA, Fernandez-Del Castillo C. AGA technical review: treatment of pain in chronic pancreatitis. Gastroenterology 1998;115:765-776.

2. Basbaum AI, Woolf CJ. Pain. Curr Biol 1999;9:R429-R431.

3. Xu GY, Winston JH, Shenoy M, Yin H, Pasricha PJ. Enhanced excitability and suppression of A-type $\mathrm{K}^{+}$current of pancreas-specific afferent neurons in a rat model of chronic pancreatitis. Am J Physiol Gastrointest Liver Physiol 2006;291:G424-G431.

4. Xu GY, Winston JH, Shenoy M, Yin H, Pendyala S, Pasricha PJ. Transient receptor potential vanilloid 1 mediates hyperalgesia and is up-regulated in rats with chronic pancreatitis. Gastroenterology 2007;133:1282- 
1292.

5. Cheng JK, Ji RR. Intracellular signaling in primary sensory neurons and persistent pain. Neurochem Res 2008;33:1970-1978.

6. Feng X, Zhou YL, Meng X, et al. Hydrogen sulfide increases excitability through suppression of sustained potassium channel currents of rat trigeminal ganglion neurons. Mol Pain 2013;9:4.

7. Joo YE. Increased expression of brain-derived neurotrophic factor in irritable bowel syndrome and its correlation with abdominal pain (Gut 2012;61:685-694). J Neurogastroenterol Motil 2013;19:109-111.

8. Bottner M, Krieglstein K, Unsicker K. The transforming growth factorbetas: structure, signaling, and roles in nervous system development and functions. J Neurochem 2000;75:2227-2240.

9. Kihara Y, Tashiro M, Nakamura H, Yamaguchi T, Yoshikawa H, Otsuki M. Role of TGF- $\beta 1$, extracellular matrix, and matrix metalloproteinase in the healing process of the pancreas after induction of acute necrotizing pancreatitis using arginine in rats. Pancreas 2001;23:288-295.

10. Vogelmann R, Ruf D, Wagner M, Adler G, Menke A. Effects of fibrogenic mediators on the development of pancreatic fibrosis in a TGF- $\beta 1$ transgenic mouse model. Am J Physiol Gastrointest Liver Physiol 2001;280:G164-G172.

11. Echeverry S, Shi XQ, Haw A, Liu H, Zhang ZW, Zhang J. Transforming growth factor-beta1 impairs neuropathic pain through pleiotropic effects. Mol Pain 2009;5:16.

12. Wang J, Yu J, Ding CP, Han SP, Zeng XY, Wang JY. Transforming growth factor-beta in the red nucleus plays antinociceptive effect under physiological and pathological pain conditions. Neuroscience 2015;291:37-45

13. Zhu Y, Colak T, Shenoy M, et al. Transforming growth factor beta induces sensory neuronal hyperexcitability, and contributes to pancreatic pain and hyperalgesia in rats with chronic pancreatitis. Mol Pain 2012;8:65.

14. Utreras E, Keller J, Terse A, Prochazkova M, Iadarola MJ, Kulkarni AB. Transforming growth factor- $\beta 1$ regulates $\mathrm{Cdk} 5$ activity in primary sensory neurons. J Biol Chem 2012;287:16917-16929.

15. Utreras E, Prochazkova M, Terse A, et al. TGF-beta1 sensitizes TRPV1 through Cdk5 signaling in odontoblast-like cells. Mol Pain 2013;9:24.

16. Xu Q, Zhang XM, Duan KZ, et al. Peripheral TGF-beta1 signaling is a critical event in bone cancer-induced hyperalgesia in rodents. J Neurosci 2013;33:19099-19111.

17. van Laethem JL, Deviere J, Resibois A, et al. Localization of transforming growth factor beta 1 and its latent binding protein in human chronic pancreatitis. Gastroenterology 1995;108:1873-1881.

18. Su SB, Motoo Y, Xie MJ, Miyazono K, Sawabu N. Expression of trans- forming growth factor-beta in spontaneous chronic pancreatitis in the WBN/Kob rat. Dig Dis Sci 2000;45:151-159.

19. Xu GY, Shenoy M, Winston JH, Mittal S, Pasricha PJ. P2X receptormediated visceral hyperalgesia in a rat model of chronic visceral hypersensitivity. Gut 2008;57:1230-1237.

20. Wang S, Zhu HY, Jin Y, et al. Adrenergic signaling mediates mechanical hyperalgesia through activation of $\mathrm{P} 2 \mathrm{X} 3$ receptors in primary sensory neurons of rats with chronic pancreatitis. Am J Physiol Gastrointest Liver Physiol 2015;308:G710-G719.

21. Miao X, Meng X, Wu G, et al. Upregulation of cystathionine-betasynthetase expression contributes to inflammatory pain in rat temporomandibular joint. Mol Pain 2014;10:9.

22. Hu J, Song ZY, Zhang HH, et al. Colonic hypersensitivity and sensitization of voltage-gated sodium channels in primary sensory neurons in rats with diabetes. J Neurogastroenterol Motil 2016;22:129-140.

23. Harper AA, Lawson SN. Conduction velocity is related to morphological cell type in rat dorsal root ganglion neurones. J Physiol 1985;359:3146.

24. Kumazawa T. The polymodal receptor: bio-warning and defense system. Prog Brain Res 1996;113:3-18.

25. Pareek TK, Keller J, Kesavapany S, et al. Cyclin-dependent kinase 5 modulates nociceptive signaling through direct phosphorylation of transient receptor potential vanilloid 1. Proc Natl Acad Sci USA 2007;104:660-665.

26. Kazbay K, Tarnasky PR, Hawes RH, Cotton PB. Increased transforming growth factor beta in pure pancreatic juice in pancreatitis. Pancreas 2001;22:193-195.

27. Inman GJ, Nicolas FJ, Callahan JF, et al. SB-431542 is a potent and specific inhibitor of transforming growth factor-beta superfamily type I activin receptor-like kinase (ALK) receptors ALK4, ALK5, and ALK7. Mol Pharmacol 2002;62:65-74.

28. Zheng Y, Zhao YD, Gibbons $M$, et al. Tof $\beta$ signaling directly induces Arf promoter remodeling by a mechanism involving Smads 2/3 and p38 MAPK. J Biol Chem 2010;285:35654-35664.

29. Buskohl PR, Sun MJ, Thompson RP, Butcher JT. Serotonin potentiates transforming growth factor-beta3 induced biomechanical remodeling in avian embryonic atrioventricular valves. PLoS One 2012;7:e42527.

30. Du X, Hao H, Gigout S, et al. Control of somatic membrane potential in nociceptive neurons and its implications for peripheral nociceptive transmission. Pain 2014;155:2306-2322.

31. Kang JS, Liu C, Derynck R. New regulatory mechanisms of TGF- $\beta$ receptor function. Trends Cell Biol 2009;19:385-394. 